\title{
Are We To Be Forever Trapped \\ Between the Two? The Internet, Modernity, AND Postmodernity IN THE \\ EARLY 21st CENTURY
}

\author{
SARAH Michele Ford \\ University of Massachusetts, Amherst
}

\begin{abstract}
Social theory has traditionally argued that the modern and the postmodern are chronologically ordered (that is, the postmodern comes after the modern) and mutually exclusive. I find, however, that contemporary American society is full of elements of both the modern/industrial and the postmodern/postindustrial. The Internet serves as an example of one social site in which these two concepts are in constant contact and often in tension. Based on an examination of the relationship between the modern/ industrial and the postmodern/postindustrial on the Internet, we can begin to determine whether or not the concepts of "modern" and "postmodern" accurately describe $21^{\text {st }}$ century society.
\end{abstract}

\section{Introduction}

The question of the relationship between the modern and the postmodern, the industrial and the postindustrial is one which social theorists has preoccupied for a number of years. The majority of work in this area has been purely theoretical and much of it has also argued that there will be a transition from the modern/industrial to the postmodern/postindustrial, clearly implying that the two are mutually exclusive and chronologically ordered. I find, however, that the "transition" from the modern/industrial to the postmodern/ postindustrial has lasted for nearly three decades, without any 
reasonable end in sight. Nearly 20 years ago, Ihab Hassan wrote that

[m]odernism and postmodernism are not separated by an Iron Curtain or Chinese Wall; for history is a palimpsest, and culture is permeable to time past, time present, and time future. We are all, I suspect, a little Victorian, Modern, and Postmodern, at once (Hassan 1985:121).

Furthermore, the social site where one might most reasonably expect postmodernity to rule, the Internet, is in fact an element of contemporary society in which the modern and the postmodern at times coexist and at other times are in tension. This coexistence points us towards new theorizing about the relationship between the modern/industrial and the postmodern/postindustrial. The ways in which the modern/industrial and the postmodern/postindustrial interact in relation to the Internet can guide us in our examination of whether we are trapped in an era of transition from one to the other or whether a situation has arisen in which the terms "modern" and "postmodern" simply no longer accurately describe social reality.

\section{The Modern/Industrial and the Postmodern/Postindustrial}

Modernity, in the sense that social scientists currently use the term, began during the Enlightenment, and is associated with liberal philosophy. "The idea [of the Enlightenment] was to use the accumulation of knowledge generated by many individuals working freely and creatively for the pursuit of human emancipation and the enrichment of daily life” (Harvey 1990:12). These goals of liberation and progress were to be achieved through reason and, above all, science. Enlightenment thinkers believed that, in order to achieve this progress, a complete break with the West's feudal, theocratic past was necessary, and they "welcomed the maelstrom of change and saw the transitoriness, the fleeting, and the 
fragmentary as a necessary condition through which the modernizing project could be achieved” (Harvey 1990:13).

Modernism as a cultural and intellectual movement found its economic counterpart in industrialism and capitalism. Industrialism is characterized by mass production and mass consumption. It began in England during the $19^{\text {th }}$ century and from there spread to the rest of Europe and the United States, reaching its peak in the United States after World War II. The system reached its pinnacle through Fordist mass production (named for Henry Ford of Ford Motor Cars) and Keynesian economics. Fordism was above all a rational system which, at least in the beginning, drew on Taylor's The principles of scientific management (Taylor and Tucker 1914).

What was special about Ford... was his vision, his explicit recognition that mass production meant mass consumption, a new system of the reproduction of labour power, a new politics of labour control and management, a new aesthetics and psychology, in short, a new kind of rationalized, modernist, and populist democratic society (Harvey 1990:125-126).

The phenomenal success that the industrial system experienced during the postwar years (and, in fact, the popular image of idyllic 1950s life is the very picture of Fordist mass consumption) occurred through a combination of Fordist corporate policies and Keynesian economics; thus Fordism "has to be seen, therefore, less as a mere system of mass production and more as a total way of life” (Harvey 1990:135).

Postmodernism began during the late 1960s as an intellectual movement opposed to modernism. From its intellectual origins, use of the term "postmodern" has expanded to describe social conditions and cultural products. At its most basic level, postmodernism tells us to question everything, especially 
Enlightenment philosophy. "Perhaps the most important hallmark of all this [postmodern and poststructural] work is its aversion to clean positivist definitions and categories" (Agger 1991:112). At this intellectual level, postmodernism is a direct critique of modern thinking. Where does scientific authority come from? What are the assumptions we make when we read or write something, and how do those assumptions bias our views of the world?

One of the foremost postmodern theorists is Jean-François Lyotard. He asks us to consider whether or not scientific knowledge is superior to other forms.

[T] he effect of dividing reason into cognitive or theoretical reason on the one hand, and practical reason on the other, is to attack the legitimacy of the discourse of science; not directly, but indirectly, by revealing that it is a language game with its own rules... and that it has no special calling to supervise the game of praxis... The game of science is thus put on a par with the others (Lyotard 1994:30).

Lyotard also states that "[I]n its immediacy, denotive discourse bearing on a certain referent (a living organism, a chemical property, a physical phenomenon, etc.) does not really know what it thinks it knows. Positive science is not a form of knowledge" (Lyotard 1994:28-29). His objection to science (and he defines science quite broadly) lies primarily in its use of grand narratives, which he explicitly rejects due to their attempts to explain the whole of society/history/the world with only one theory. Lyotard's cynicism towards meta-narratives stems directly from what he and many other postmodernists see as the failure of Enlightenment philosophy. The Enlightenment promised the liberation of mankind through science and reason; instead it brought two World Wars, genocide, atomic bombs, and countless failed socialist experiments/ revolutions. Lyotard proposes a turn to local forms of knowledge as an alternative to modernism. 
A recognition of the heteromorphous nature of language games is a first step in that direction [towards a nonconsensus-based practice of justice]... The second step is the principle that any consensus on the rules defining a game and the "moves" playable within it must be local, in other words, agreed on by its present players and subject to eventual cancellation. The orientation then favors a multiplicity and finite meta-arguments, by which I mean argumentation that concerns metaprescriptives and is limited in space and time... (Lyotard 1994:37).

This system, believe Lyotard and other postmodernists, is free from the bias and totalizing tendencies of the meta-narratives. I would add that the "eventual cancellation" of these games also serves to prevent abuse of the system. Lyotard begins, with his discussion of local knowledge, to touch on another important feature of postmodernism/postindustrialism: decenteredness. Where modernity had a unified center, postmodernism does not. This idea carries through much of the discussion to follow and will be expanded upon below.

Just as industrialism is the economic counterpart to modernism, postindustrialism is the economic counterpart to postmodernism. The postindustrial mode of production has been described primarily as a change in the types of "products" put out by the system. Daniel Bell (Bell 1976) argues that in the industrial era, the economy was goods-producing and that in the postindustrial era it is servicebased. David Harvey (Harvey 1990) makes a similar argument, pointing out that information and knowledge have taken on the role of "commodity" and that corporations have become decentered.

\section{The Internet}

The Internet is a relatively new factor in contemporary society. It is also one site in which many of the tensions between the modern 
and the postmodern are expressed. On and within the Internet, there are many elements of the modern/industrial and also of the postmodern/postindustrial.

What we now call "the Internet" began as a Cold-War era Advanced Research Projects Agency (ARPA) undertaking. Its purpose was to protect the Defense Department's computer communications from attack. At the time that it was developed, ARPANet was a triumph of technology and engineering: a network that, rather than connecting computers directly with dedicated lines (the way a telephone works), broke up the information to be sent into smaller units. These "packets" were then transmitted one by one and the data were reassembled when they arrived at their destination. There was no set route that the packets took between the source and destination. This made the network robust; if one route was damaged, another would surely be available. Since its inception, ARPANet has been combined with a number of other networks developed by other groups, including NSFNet, which was developed and run by the National Science Foundation, and computer networks developed at universities across the country. Use of this larger computer network became common in academic circles and, with the advent of publicly-available Internet Service Providers, came into the common use we see today.

Even at this level, the Internet shows the coexistence of the modern and the postmodern. At a conceptual level, it is impossible to separate the Internet from its roots in that most modern of conflicts, the Cold War. The development of the technology behind the Internet clearly arose from the modern impulse towards progress. At the same time, however, the Internet is by its very nature decentered; there is no "home of the Internet." Its soul lies not in its hardware (the computers that are connected to the network and the wires, fiber optics, and satellite links that carry data back and forth) but in is software and in the ways that people use it and relate to each other through it. 


\title{
The Internet and Time and Space
}

Before the Industrial Revolution reorganized the labor process, hours and minutes were of relatively little importance to the average person. With the coming of the modern era and industrial production, however, these demarcations of time became more and more important until time itself became a sort of commodity something to be bought and saved, something that seems always to be in short supply. Eventually, in postmodern times, this becomes "space-time compression." This compression is tied to the postindustrial economy and the accompanying speedup in production.

\begin{abstract}
Accelerating turnover time in production entails parallel accelerations in exchange and consumption. Improved systems of communication and information flow, coupled with rationalizations in techniques of distribution...made it possible to circulate commodities through the market system with greater speed (Harvey 1990:285).
\end{abstract}

Harvey credits this speedup in production with two major consequences: "the mobilization of fashion in mass" and "a shift away from the consumption of goods and into the consumption of services" (Harvey 1990:285).

In addition to the general speedup of the pace of life, Harvey sees the space of the whole world being brought into one place, thanks to new technology.

It costs the same to communicate over 500 miles as it does over 5,000 miles via satellite... It is now possible for a large multinational corporation like Texas Instruments to operate plants with simultaneous decision-making with respect to financial, market input costs, quality control... Mass television ownership coupled with satellite communication makes it possible to experience a rush of images from different spaces, almost simultaneously, 
collapsing the world's spaces into a series of images on a television screen (Harvey 1990:293).

In many ways, Harvey is describing what Kenneth Gergen calls "social saturation" (Gergen 1991). One might be tempted to conclude that this compression of space means that space/place become unimportant. Quite the opposite, says Harvey. "Heightened competition under conditions of crisis has coerced capitalists into paying much closer attention to relative locational advantages, precisely because diminishing spatial barriers give capitalists the power to exploit minute spatial differentiations to good effect” (Harvey 1990:293-294).

The Internet greatly facilitates this compression of time and space. Through chat software and services, it has made synchronous communication over great distances a reality. Additionally, the Internet has sped up the pace of asynchronous communication. Where the elapsed time between the writing and receipt of a "snail mail” letter might be days or even weeks, electronic mail can be composed as quickly as the writer can type and can arrive in the recipient's inbox in a matter of seconds. This immediacy has resulted in changed expectations of the pace of correspondence; since e-mail is so quick to write and send, the expectation has developed that replies should be instantaneous as well.

These changed expectations about correspondence are accompanied by changes in working patterns as described by Daniel Bell. Bell argues that in a postindustrial economy, there is a proliferation of professional/technical work (Bell 1976). Ultimately, this means an increase in the number of workers who find themselves in some form of office-based employment. The ready availability of Internet connections in these work environments means that workers can have their e-mail software running in the "background" as they work on other tasks, thus compressing more "processes" into the same amount of time. 
Additionally, availability of the Internet at work allows for the compression of the public and private spheres. It is now possible to use e-mail or chat software to keep up with friends and family, bringing the "private" sphere into the public arena of work, at least as a "background task." Some employers seek to control this use of the Internet by monitoring employees' e-mail accounts and by forbidding or preventing the use of chat software; others seem to have decided that the increased productivity that the Internet allows makes up for work time lost to its recreational use.

\section{The Internet as a Site of Economic Activity}

The postindustrial economy looks quite different from industrialism. Changes in the technologies of production and in the world economy have resulted in a shift away from mass production as well as changes in types of labor. Daniel Bell describes postindustrial society as a shift from a goods-producing to a service-based economy where the professional and technical class are pre-eminent. Within that system, technology, information, and knowledge are very important (Bell 1976). David Harvey, on the other hand, conceptualizes postindustrialism in terms of flexible accumulation, describing it as a reaction to the rigidities of Fordism. Flexible accumulation is characterized by a shift to part time/flex time/temporary labor and by changes in the rate of production and consumption. "The economies of scale sought under Fordist mass production have... been countered by an increasing capacity to manufacture a variety of goods cheaply in small batches" (Harvey 1990:155). This shift in production is intimately tied to changes in patterns of product innovation and the development of "highly specialized and small-scale market niches” (Harvey 1990:156). Turnover time and rates of production accelerated, and with that came a speedup in the rate of change in consumer tastes. Where consumers expected Fordist products (automobiles, large appliances) to last from five to seven years on average, today's products, especially "thought-ware" products, have half-lives that 
are measured in months; patterns of consumption have followed this trend.

For all intents and purposes, the Internet cannot function as a site of production in the modern/industrial sense, although it certainly does serve as a site of mass consumption. Many of the elements of the postmodern/postindustrial that Bell and Harvey describe are present on the Internet. The most apparent of these are the Internet as a site of commerce centered on sales and services and the use of the Internet to make information more readily available to the average consumer.

\section{Shopping on the Internet}

The Internet serves as a site of mass consumption by allowing the consumer great freedom to find and purchase products. It removes many temporal and geographic limitations on commerce, making it possible for a consumer in Massachusetts to buy a computer from a merchant in California in the middle of the night. The Internet also empowers the consumer to make better decisions by increasing the availability of information. A consumer considering purchasing a new computer, for example, can read reviews of various models written both by experts in the field and by their fellow consumers before making a decision. Once they have settled on the specific product they want to purchase, the consumer can comparison-shop for the lowest possible price. The increased convenience and information also makes it easy for Internet users to become more frequent consumers. Shopping on the Internet is almost too easy, especially when many e-commerce sites offer "oneclick ordering."

In addition to empowering the average person to become a savvier consumer, the Internet has enabled them to become vendors as well. Auction sites like eBay allow anyone with Internet access to sell just about anything they might want to. Some Internet users treat these sites like an online tag sale, offering up old clothes, 
books, toys, and so on. Others have taken the existence of these sites as an opportunity to launch what amount to small businesses, selling either home-made products or products they have bought in large quantities and are reselling at a profit. Other sites, like amazon.com, allow individuals to sell more specific items (like books) at their own price; in these cases, the e-commerce site acts as a broker of the sale between individuals.

These decentered, postindustrial uses of the Internet, however, carry with them a set of decidedly modern problems, including the risk of invasion of privacy, credit card theft, and even identity theft. These risks are inherent in any system that requires the consumer to transmit information using a medium over which s/he has no control (such as the Internet). Internet-based businesses have set out to protect their customers by offering secure transmission of sensitive data such as credit card numbers and by publicly stating what they do with personal information collected by their websites. For their part, credit card companies have begun to develop cards and programs offering limited or no consumer liability in cases of online fraud.

\section{The Virtual Commodity}

In addition to being able to shop without the limitations of the "real world," with e-commerce has come the possibility of the virtual commodity. Rather than buying a "real" book from their local bookstore or Amazon.com, consumers can buy an e-book -a digital book, all ones and zeroes until the consumer's computer represents those data graphically. Similarly, rather than purchasing CDs, consumers can now purchase digital versions of the same music, which, upon paying for the product, they download to their computers to play electronically. As Jean Baudrillard puts it, "What every society looks for in continuing to produce, and to overproduce, is to restore the real that escapes it. That is why today this 'material' production is that of the hyperreal itself" (Baudrillard 1994:23). Virtual products are, at least in Baudrillard's 
view of things, not real commodities. They are instead simulations of the real; they are hyperreal. When you purchase digital music, or even recorded music, you are purchasing a simulation of a live performance. When you purchase an e-book, you are purchasing a simulation of a real, physical book.

Virtual commodities are the next step in the mechanical reproduction of cultural artifacts described by Walter Benjamin, who wrote that "[e]ven the most perfect reproduction of a work of art is lacking in one element: its presence in time and space, its unique existence at the place where it happens to be. This unique existence of the work of art determined the history to which it was subject throughout the time of its existence” (Benjamin 1969:220). Benjamin conceptualizes the work of art as a physical entity, and argues that some essence of that entity is lost through the process of reproduction. He further points out that "technical reproduction can put the copy of the original into situations which would be out of reach for the original itself. Above all, it enables the original to meet the beholder halfway, be it in the form of a photograph or a phonographic record” (Benjamin 1969:220-221). In other words, technical reproduction decenters the work of art, divorcing it from its original context. On the Internet, however, we find art that was in fact mechanically (or, more specifically, digitally) produced, works that have never had a physical incarnation or a context in which they were displayed. ${ }^{1}$ Furthermore, any "reproduction" of these works will be an exact copy of them, since at their core, they are nothing but binary code stored on digital media. Thus, for example, music that was created on a computer and is distributed over the Internet in .mp3 format has never been "real” according to Benjamin's scheme. The very virtuality of these products makes them postmodern.

As is the case with e-commerce, the development of virtual commodities has been plagued by modern problems. While many mainstream publishers have developed cyber presses and ondemand electronic publishing, technological limitations have 
prevented e-books from becoming a common sight in classrooms and on the subway. These fall into two related categories: hardware and file format. There are currently roughly half a dozen dedicated e-book readers available (excepting laptop computers, pocket PCs, and Personal Digital Assistants). I was able to find information on two models from RCA(the REB 1100 and the REB 1200) as well as a Franklin eBookMan, the Gemstar eBook, and the hiebook. These devices range in price from roughly $\$ 130$ for the eBookMan to $\$ 400$ for the REB 1200 and the Gemstar eBook. ${ }^{2}$ They are reported to have a number of problems, ranging from text that is hard to read for extended periods of time to devices that are too heavy to be practical (Robinson and Halle 2002). Compounding these problems is the lack of a standardized file format; the five above-listed models use three different file formats. The RCA models and the Gemstar all used Gemstar eBook format; the eBookMan used mobipocket (which is also compatible with Palm OS devices, handheld PCs and Pocket PCs), and the hiebook used its own proprietary format. For the consumer, this means that once they select an e-book reader, they have in all likelihood committed themselves to only a subset of the electronic titles available at any given time.

Along with the technical difficulties facing the popularization of digital commodities come some socio-legal ones. The primary problem for publishers and creators of electronic (and some nonelectronic) media has been the issue of copyright violation. This debate has centered primarily on the issue of digital music, particularly music encoded as .mp3 files. This issue came to the forefront of the world's attention with the development and popularity of Napster, a free program that allowed users to designate certain directories on their computers as "shared," allowing any other user of the software (no matter their geographic location) to copy the (.mp3) files located within that directory to their own computers. This system allowed the free exchange of .mp3 files, some of which users had copied (or "ripped") from compact discs, others of which they had acquired through various electronic 
means. It was the former method that ultimately led to Napster's downfall. In 1999, the Recording Industry Association of America, rapper Dr. Dre, and heavy-metal band Metallica sued Napster. All alleged copyright infringement. In the end, Napster was ordered to shut down its free services and was ultimately bought by Bertelsmann, the German media company that owns BMG (Robinson and Halle 2002).

The debate over Napster illustrates many of the conflicts between the modern and the postmodern that relate to the Internet. Napster's very existence and the free trading of music tapped into postmodernism's challenges to corporate and scientific authority; the model upon which the software was designed was decentered and egalitarian. It challenged the conception of computer storage as belonging to just one person, although that computer owner did make a conscious choice to allow others access to their machine. On the other hand, the allegations of copyright infringement were grounded in modern beliefs about intellectual property and corporate control over the artistic product. Even within the music industry, however, there was not unanimity on what, if anything, to do about Napster. While Dr. Dre and Metallica raged against the system, other lesser known and independent artists used the service to build their audience (Robinson and Halle 2002).

\section{Services Available on the Internet}

One of the most important parts of the postindustrial economy is information. As David Harvey puts it, "[A]ccurate and up-to-date information is now a very highly valued commodity. Access to, and control over, information, coupled with a strong capacity for instant data analysis, have become essential to the centralized coordination of far-flung corporate interests” (Harvey 1990:159). In fact, production and control of knowledge have become industries in and of themselves. "Universities and research institutes compete fiercely ... for being the first in patenting new scientific discoveries” (Harvey 1990:160). It is not only within the academy 
that knowledge and information have become important as commodities, however. "Control over information flow and over the vehicles for propagation of popular taste and culture have likewise become vital weapons in competitive struggle" (Harvey 1990:160). Bell argues that information/knowledge is not just necessary on the macro level. "The post-industrial society...is a knowledge society in a double sense: first, the sources of innovation are increasingly derivative from research and development...; second, the weight of the society... is increasingly in the knowledge field" (Bell 1976:212). Bell illustrates the importance of knowledge in postindustrial society by citing exponential growth in the proportion of the population attending college as well as the proportion of college graduates going on to do graduate-level work. The Internet has made access to information infinitely easier, and in doing so has democratized many previously specialized services.

Planning a vacation in the pre-Internet marketplace used to involve a trip to the travel agent, who, for a fee, would make contact with the airlines, hotels, and car rental agencies for the consumer. Travel planning was a specialized skill. Today, however, any consumer with access to the World Wide Web can plan their own trips, either by booking directly with their preferred airline, hotel, and car rental agency, or by using one of the many web-based services that will compare prices across airlines, hotels, and rental agencies. More web-savvy users may even compare prices across web-based services in order to get the best deal possible.

The Internet has also depersonalized and democratized financial services. Loan applicants may use the Internet to "comparison shop" for the best interest rate, fewest points, etc. LendingTree.com (http://www.lendingtree.com) advertises using the slogan "When lenders compete, you win.” This website provides consumers with a comparison of loan offers from "four major lenders." Ditech.com (http://www.ditech.com) offers second mortgages over the Internet; both advertise heavily both on the Internet and on television. More mundane financial services are available online as well, though 
they are often tied to the consumer's "physical” bank. These services include automatic bill payment (essentially by authorizing electronic fund transfers from the consumer's account to that of the service provider each time a bill is due) and account maintenance.

There is at least one purely virtual bank doing business in the United States at this time. E*Trade ${ }^{\circledR}$ (http://www.etrade.com) began serving the individual investor in 1992 and in February of 2002 debuted E*Trade Financial, a full-service online bank. The website now offers investment services as well as checking, saving, and money market accounts (all of which are FDIC insured), certificates of deposit, online bill payment, and direct deposit. Customers can make deposits by mail or by wire transfer, and access their funds by writing checks or by using an ATM. In addition to these everyday services, E*Trade offers mortgages, refinancing, car loans, and credit cards. It is in all respects a full-service financial institution, just one that lacks a physical presence.

These economic activities encapsulate the coexistence of and conflict between the modern/industrial and the postmodern/ postindustrial on the Internet. The modern impulse from which the Internet grew is still apparent in many of the ways that it is used today - it is a tool for progress. Progress means making shopping easier. Progress even means the ability to use online banking and travel services. Within this framework of modernity, however, we also see the postmodern/postindustrial. The Internet makes information much more easily accessible than it has ever been before. It also makes possible the distribution of virtual commodities, which are entirely removed from modernity. We have seen that it is in relation to these virtual commodities that conflicts between the modern and the postmodern take place. 


\section{The Internet as a Site of Cultural Production}

One of the most defining characteristics of the postmodern/ postindustrial world is the importance and increasing availability of information. A number of theorists have also argued that an element of postmodern society is a breakdown of the differentiation between author and reader, artist and critic (Benjamin 1969; Derrida 1976). This relates also to Lyotard and the other postmodernists' rejection of any form of authority and their emphasis on local knowledge (Agger 1991; Lyotard 1994). The Internet is a site of abundant texts; it lets anyone be an author, even encourages individuals who might otherwise have never voiced their opinion in a public manner to do so. Electronic mail, which is widely and freely available, makes contacting a complete stranger more possible than it has ever been before. Without the Internet, a reader might write a letter to the editor of their local paper in response to an article that offended them; now they can send an e-mail directly to the author. Individuals may also become authors in other ways. The World Wide Web is bursting with opportunities for self-expression; news sites offer bulletin board discussions, chat services provide unstructured discussions as well as ones on specific subjects and even with well-known media personalities.

Perhaps the most dramatic change in authorship brought about by the Internet is the ability for every person to carve out a niche for themselves in which they can become an author and say whatever they want. There have always been forums for political discussion; in some ways Internet bulletin boards and chats simply serve as a substitute for the discussion in the local pub or for writing a letter to the editor. The ability for anyone to create his/her own web page, however, is unique to the Internet, and also the most democratizing aspect of it, the one that most breaks down the distinction between reader and author, artist and critic. Not only does the existence of the World Wide Web allow anyone to become an author, but, just as there are many services that offer free 
electronic mail, there are services which offer free web space. Many of these services also offer users the ability to create web pages without any knowledge of hypertext markup language (HTML), the computer language in which web pages are encoded. This makes authorship even more accessible, because all it requires of the user is the knowledge of how to use a word processing program (which can then save the documents as .html files). "Free" web space must be supported financially, however. Most of these services do so by selling advertising space on all of their "free" pages; users of the service agree to allow this action. In addition to allowing anyone with access to become an author, the Internet makes it possible for anyone with access to become a critic, both of material on the Internet and of other media such as television and movies.

\section{Identity and the Internet}

The Internet has also become a site for the enactment of identities. Since it is first and foremost a means of communication, this should not be surprising. There has been a substantial amount of research on various aspects of identity and how it plays on the Internet: general research on identity online (Bolter 1996; Cutler 1996); gender differences in communication styles (Herring 1994; Herring 1994); types of people likely to engage in cybersex (Lipton 1996; Blair 1998; Lamb 1998), identity and virtual communities (Holmes 1997; Wellman and Gulia 1999); and gender differences in realtime chat environments (Kendall 1998; Kendall 1998; Menon 1998; O’Brien 1999; Soukup 1999; Ford 2002). There are a number of unique features of Internet interaction and identity. First, the Internet allows interaction (both synchronous and asynchronous) between individuals who are separated by great distances, even continents. Second, self-presentation on the Internet consists primarily of what Goffman called "expressions given” and is devoid of "expressions given off” (Goffman 1958). Finally, the Internet makes it possible for users to conceal their "true" identities - for women to masquerade as men, for men to masquerade as women, 
for people who are straight to masquerade as being queer and for folks who are queer to pass for straight.

A major theme that runs through research on the Internet and identity is the question of the modern self versus the postmodern one. The modern self is characterized by "fragmentation, ambivalence, and estrangement” (Gecas and Burke 1995:57). It does, however, have an authentic core; it is possible to say, for example, that I have a coherent, identifiable self. The postmodern self, on the other hand, is decentered, described as "continuously emergent, re-formed, and redirected as one moves through the sea of ever-changing relationships" (Gergen 1991:139). Some theorists have gone so far as to describe it as schizophrenic.

[P]ostmodernism typically strips away [the possibility of pursuing better futures] by concentrating on the fragmentation and all those instabilities (including those of language) that prevent us from even picturing coherently, let alone devising strategies to produce, some radically different future (Harvey 1990:54).

Jameson sets up the postmodern self in opposition to modernism's "depth models" such as Freud's latent/manifest model and the dichotomy between authenticity and inauthenticity. "What replaces these various depth models is for the most part a conception of practices, discourses and textual play, whose new syntagmatic structures we will examine later on: suffice it merely to observe that here too depth is replaced by surface, or by multiple surfaces" (Jameson 1993:70). He goes on to argue that all modern conceptions (and thus individual experiences such as alienation and anxiety) "are no longer appropriate in the world of the postmodern" (Jameson 1993:71). In the end, Jameson goes so far as to say that postmodernism means the end of the self. "As for expression and feelings or emotions, the liberation, in contemporary society, from the older anomie of the centered subject may also mean, not merely a liberation from anxiety, but a liberation from 
every other kind of feeling as well, since there is no longer a self present to do the feeling” (Jameson 1993:72).

Much of Internet identity research can be broken down into two camps: the liberatory school and the critical feminist school. Liberatory theorists argue that the Internet will make it possible for people to be liberated from the bonds of race, class, gender, and sexuality. The scholars who support this thinking by and large look favorably on technology and its potential to facilitate social change. As such, they see the Internet as having the capacity to liberate us from the bonds of socially constructed categories of gender, race, class, and sexuality. Critical feminists, on the other hand, argue that gender switching online (and race switching, and presenting one's identity as anything other than what it "really" is) reifies previously existing categories. The reification effect is seen as especially true in the case of men choosing to represent themselves as women. Additionally, the critical feminists argue that men dominate women in online interaction much as they do in face-to-face interaction. Thus, they characterize cyberspace as "sinister" and as reproducing and reinforcing male communicative hegemony (Zdenek 1999). Feminist critics have proposed a number of possible solutions to this problem, ranging from an awareness of the Internet as a primarily middle class masculine space to analyzing Internet communication within speech communities, blind to gender (Kendall 1998; Zdenek 1999).

The liberatory view itself encapuslates the conflict between modern and postmodern. It advocates a very modern idea in the form of progress towards a social ideal; in this case, that ideal is the elimination of gender categories. That goal, however, is a postmodern one - the questioning and elimination of categories. In fact, my research on the creation and maintenance of gendered identities in Web-based chat rooms has shown that these interactants are struggling with the very issues encapsulated in the critical feminist/liberatory debate. Most users are still very much bound by the modern notion of categories. They routinely ask for 
other interactants' ASL (age/sex/location), and say that they are interested in chatting with a certain type of person. At the same time, some interactants actively reify gender categories by presenting hypersexualized femininity or by playing on traditional feminine stereotypes as well as by acting out the part of the horny male. Other users actively resist such reification.

\section{Conclusion}

At first blush, the Internet appears to be primarily a postmodern phenomenon. In the arena of e-commerce, the Internet empowers the consumer to be better-informed and make price comparisons, which illustrates the importance of information in the postindustrial economy. The Internet also allows consumers to shop nationwide or even internationally, effectively collapsing the space of the world into their personal computer. On a cultural level, the Internet has facilitated the distribution of digitally (re)produced art. Were this the whole story, the Internet would be of little utility in an attempt to disentangle the threads of the modern/industrial and the postmodern/postindustrial. But the Internet is not simply a postmodern phenomenon. E-commerce carries the risk of credit car fraud and theft; distribution of digitally (re)produced art has raised issues of copyright law that are grounded in modern conceptions of authority and ownership. These conflicts and tensions are what make the Internet relevant to the more theoretical question of the utility of the categories of modern, postmodern, industrial, and postindustrial. It seems that each time the modern/ industrial and the postmodern/postindustrial come into conflict on the Internet, it is because "modern" standards and rules are being applied to "postmodern” objects and activities. A more detailed examination of the contexts in which the modern/industrial and the postmodern/postindustrial come into conflict reveals that in fact these tensions are the result of the dramatic differences in the two modes of production as they are expressed on the Internet. 
In order to understand the source of these conflicts, we must look back to the origins of modernity. The modern/industrial system arose from the feudal mode of production that characterized the Middle Ages. The feudal and the industrial systems had one thing in common: production was, to a greater or lesser extent, focused on survival. The feudal system primarily governed agriculture and the production of other survival needs. These processes were also the first to be industrialized. While the feudal and industrial modes of production have relatively little in common, they do both emphasize goods necessary for survival. Even objects that we might consider "luxury" items such as automobiles are in fact necessary for survival in that they are (in many cases) necessary to carry us to work. Eventually, however, industrial production becomes so efficient that survival is no longer a pressing concern.

The postindustrial mode of production, on the other hand, assumes that survival goods are available in sufficient supply; Bell argues that the shift to a postindustrial economy cannot occur until survival needs are consistently met (Bell 1976). Only under these conditions do consumers turn their attention to services rather than to material goods. To say simply that a service economy develops when survival needs are being met is misleading, however. No society can function without some supply of material goods; in order for an economy to transition from industrial to postindustrial, another economy must take up the production of the goods necessary for survival. Those goods are then imported by the postindustrial society. In this way, even though we may argue that contemporary American society is postindustrial, we are still linked to our modern/industrial past and even to feudal Europe.

The Internet, as has already been illustrated, has strong ties to modernity. It grew out of the modern impulse towards technology and progress and in many ways is still governed by an industrial mindset; many of the products that can be bought online qualify as "survival needs." At the same time, however, contemporary use of the Internet is much more postmodern, as it is dominated by 
consumption of non-survival goods, financial services, insurance, and education. The Internet also allows the postmodern/ postindustrial to be extended into its next phase, that of virtuality in the form of virtual commodities, online identities, and digital art. The two arenas come into conflict because, no matter how deep we progress into the postmodern/postindustrial, our survival needs must still be met through modern/industrial means. This tension is especially apparent in conflicts like the one surrounding Napster. Ultimately, the artists and recording companies protesting the software were concerned about lost royalty income, a very modern and survival-oriented priority (though both the artist and the recording executives would have been hard pressed to argue that their very existence depended on the royalties they allegedly lost due to Napster's existence).

Without a detailed examination of the Internet, it might be tempting to conclude that it is an example of a postmodern phenomenon. Indeed, due to its decenteredness and its removal from the industrial mode of production (though not from capitalism and mass consumption), the Internet does seem to be quite postmodern. The discovery of strong strains of modernity still extant within the Internet suggests that in fact the modern/industrial and postmodern/ postindustrial are not mutually exclusive and chronologically ordered. If the one site where it seems that the postmodern/ postindustrial should have the strongest hold - the Internet - cannot be separated from modernity, the modern/industrial - postmodern/ postindustrial dichotomy must be false. To continue to conceptualize contemporary American social condition in terms of this dichotomy would be inaccurate at best. The long-term coexistence and continual negotiation between the two suggest that we are not transitioning from a modern/industrial era to a postmodern/postindustrial one. Rather, they are working together to form some new social system that lies outside the descriptive universe of our current terminology. 


\section{Sources Cited}

Agger, B. (1991). "Critical Theory, Poststructuralism, Postmodernism: Their Sociological Relevance.” Annual Review of Sociology 17: 105131.

Baudrillard, J. (1994). Simulacra and Simulation. Ann Arbor, University of Michigan Press.

Bell, D. (1976). The Coming of Post-Industrial Society: A Venture in Social Forecasting. New York, Basic Books.

Benjamin, W. (1969). Illuminations. New York, Schocken Books.

Blair, C. (1998). Netsex: Empowerment Through Discourse. Cyberghetto or Cybertopia? Race, Class, and Gender on the Internet. B. Ebo. Westport, CT, Praeger.

Bolter, J. D. (1996). Virtual Reality and the Redefinition of Self. Communication and Cyberspace: Social Interaction in an Electronic Environment. L. Strate, R. Jacobson and S. B. Gibson. Cresskill, NJ, Hampton Press.

Cutler, R. H. (1996). Technologies, Relations, and Selves. Communication in Cyberspace: Social Interaction in an Electronic Environment. L. Strate, R. Jacobson and S. B. Gibson. Cresskill, NJ, Hampton Press.

Derrida, J. (1976). Of Grammatology. Baltimore, Johns Hopkins University Press.

Ford, S. (2002). ASL Everyone!: Construction and Maintenance of Gendered Identities in Web-Based Chat Rooms.

Gecas, V. and P. Burke (1995). Self and Identity. Sociological Perspectives on Social Psychology. K. Cook, G. Fine and J. House. Gergen, K. J. (1991). The Saturated Self: Dilemmas of Identity in Contemporary Life. New York, Basic Books.

Goffman, E. (1958). The Presentation of Self in Everyday Life. New York, Anchor Books.

Harvey, D. (1990). The Condition of Postmodernity. Cambridge, MA, Blackwell.

Hassan, I. (1985). “The Culture of Postmodernism.” Theory, Culture, and Society 2(3): 119-131.

Herring, S. (1994). Gender Differneces in Computer-Mediated Communication: Bringing Familiar Baggage to the New Frontier. 2000. 
Herring, S. (1994). Politeness in computer culture: Why women thank and men flame. Cultural Performances, Berkeley, CA, Berkeley Women and Language Group.

Holmes, D. (1997). Virtual Identity: Communities of Broadcast, Communities of Interactivity. Virtual Politics: Identity and Community in Cyberspace. D. Holmes. Thousand Oaks, CA, Sage. Jameson, F. (1993). Postmodernism, or The Cultural Logic of Late Capitalism. Postmodernism: A Reader. T. Docherty. New York, Columbia University Press.

Kendall, L. (1998). “Are You Male or Female?” Gender Performances on Muds. Everyday Inequalitites: Critical Inquiries. J. O’Brien and J. Howard. Malden, MA, Blackwell.

Kendall, L. (1998). Hanging Out in the Virtual Pub: Identity, Masculinities, and Relationships Online. Dept. of Sociology. Davis, CA, University of California at Davis.

Lamb, M. (1998). "Cybersex: Research Notes on the Characteristics of the Visitors to Online Chat Rooms." Deviant Behavior: An Interdisciplinary Journal 19: 121-135.

Lipton, M. (1996). Forgetting the Body: Cybersex and Identity. Communication and Cyberspace: Social Interaction in an Electronic Environment. L. Strate, R. Jacobson and S. B. Gibson. Cresskill, NJ, Hampton Press.

Lyotard, J. (1994). The Postmodern Condition. The Postmodern Turn: New Perspectives on Social Theory. S. Seidman. New York, Oxford University Press.

Menon, G. M. (1998). "Gender Encounters in a Virtual Community.” Computers in Human Services 15(1): 55-69.

O’Brien, J. (1999). Writing in the body: Gender (re)production in online interaction. Communities in Cyberspace. M. A. Smith and P. Kollock. New York, Routledge.

Robinson, L. and D. Halle (2002). "Digitization, the Internet, and the Arts: eBay, Napster, SAG, and e-Books.” Qualitative Sociology 25(3): 359-383.

Soukup, C. (1999). "The Gendered Interactional Patterns of ComputerMediated Chat Rooms: A Critical Ethnographic Study.” The Information Society 15: 169-176.

Taylor, F. W. and W. J. Tucker (1914). The principles of scientific management. New York; London, Harper \& brothers. 
Wellman, B. and M. Gulia (1999). Net-Surfers Don't Ride Alone: Virtual Communities as Communities. Networks in the Global Village: Life in Contemporary Communities. B. Wellman. Boulder, CO, Westview. Zdenek, S. (1999). "Rising up from the MUD: inscribing gender in software design.” Discourse and Society 10(3): 379-409.

\section{Notes}

${ }^{1}$ My definition of art is broader than Benjamin's; I include music as well as the visual arts.

${ }^{2}$ Prices for the Franklin and Gemstar readers were the lowest found at EBookMall.com (http://www.ebookmall.com/knowledge-collection/ device-comparisons.htm); the price for the RCA REB1200 is from the RCA website (http://www.rca.com). 